\title{
THE ASIA-PACIFIC IMPACT
}

The Nature Index 2015 Asia-Pacific reveals strong overall results from the traditional science leaders in this region. In addition, some smaller countries excel in specific areas.

\section{THE REGION'S TOP-10 PRODUCERS}

China leads the Asia-Pacific in weighted fractional count (WFC) - second only to the United States globally - and many countries in the region focus on chemistry and physical sciences.
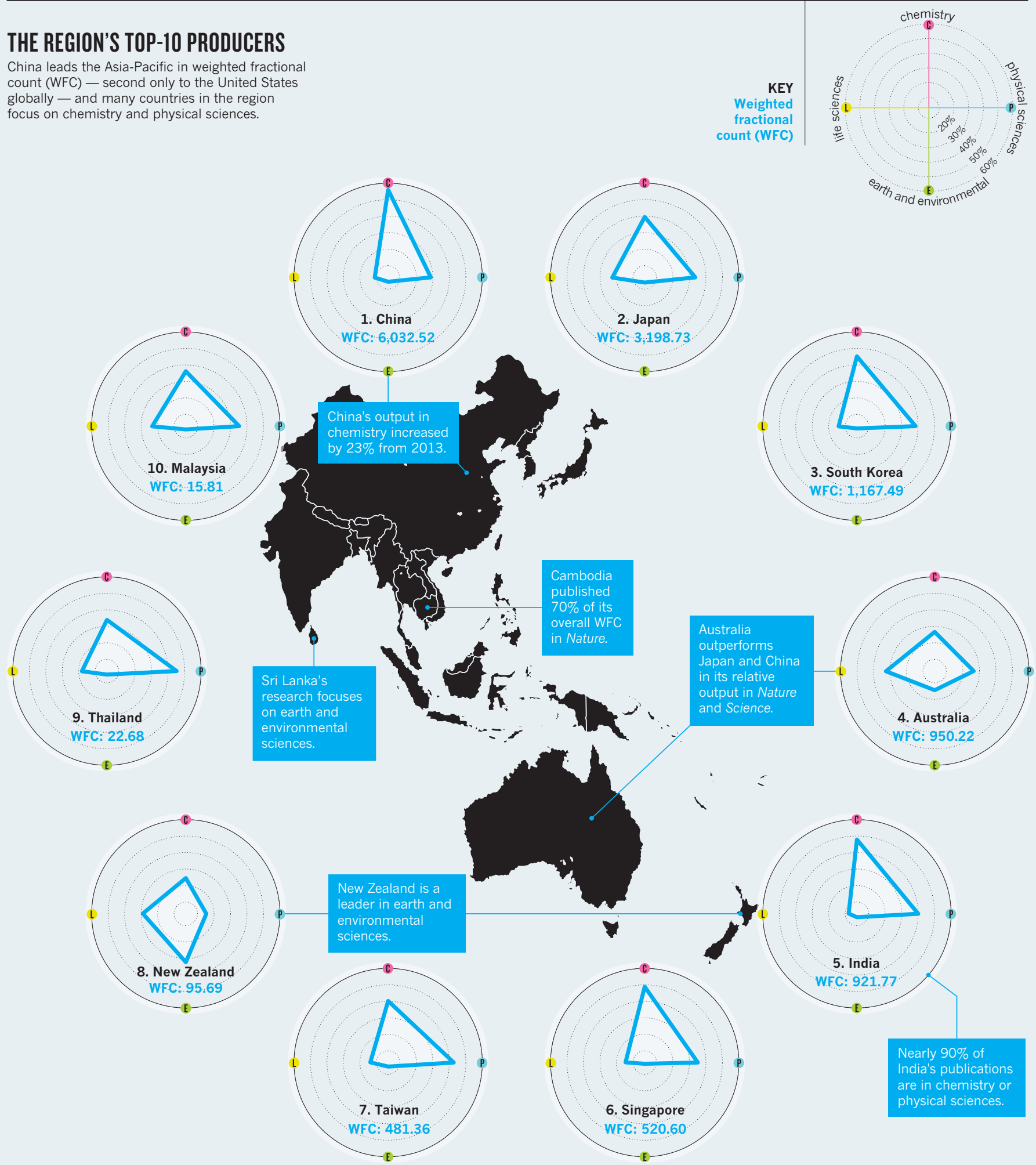


\section{SUBJECT SHIFTS}

Compared to the global balance of articles by category, scientists in the Asia-Pacific region publish less in the life sciences and more in chemistry.

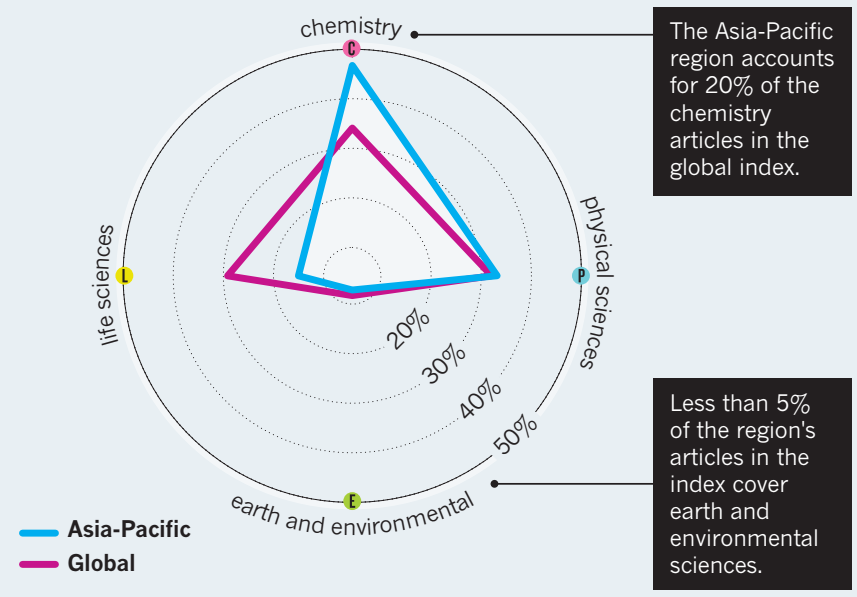

\section{ASIA-PACIFIC VS. THE WORLD}

Scientists in the Asia-Pacific region account for about a quarter of the global WFC.

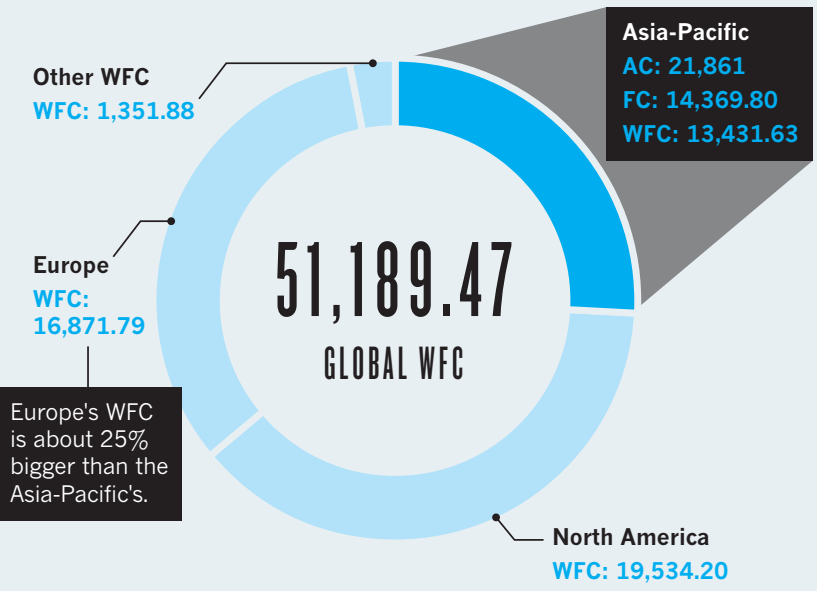

\section{STRENGTHS BY SUBJECT}

Based on WFC, China leads three of the four categories, and dominates chemistry with $53 \%$.

\section{China \\ Japan \\ South Korea \\ Australia \\ India \\ Singapore \\ Taiwan \\ Others}

Japan surpasses China by less than $5 \%$ in life sciences.

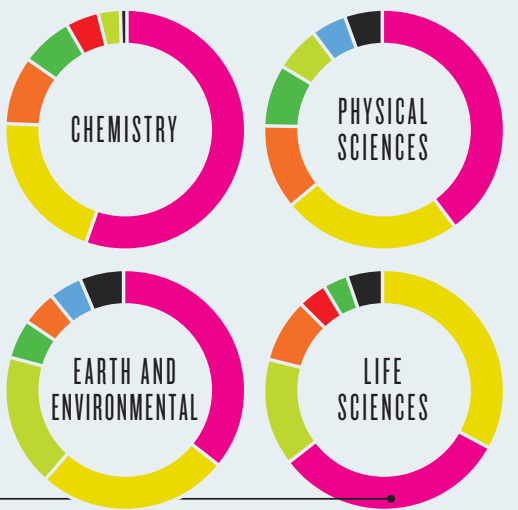

\section{THE FRUITS OF INVESTMENT}

Countries with higher gross domestic expenditure on R\&D (GERD) publish more articles.

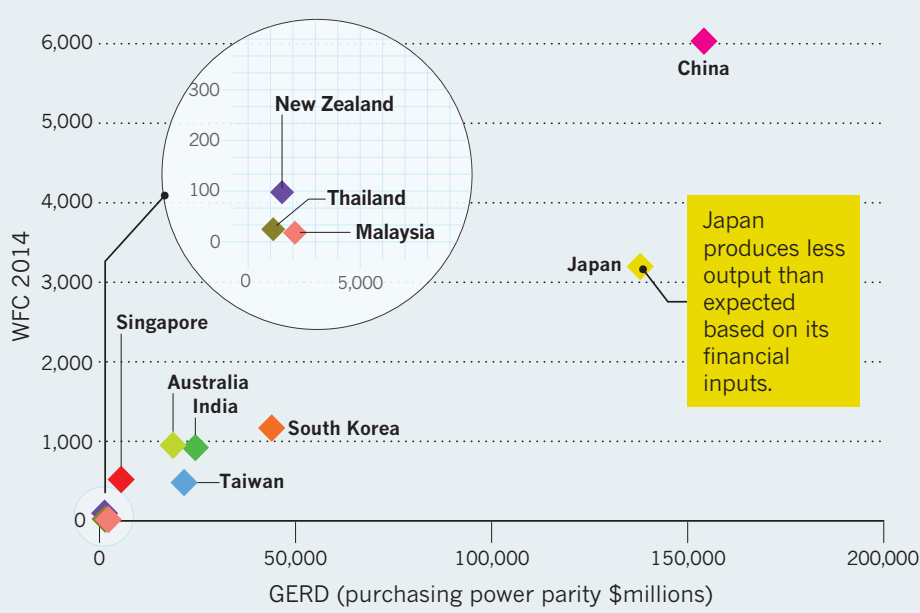

COOPERATION FROM AFAR

For nearly every country, collaborations outside the Asia-Pacific region far exceed those with scientists from within the region.

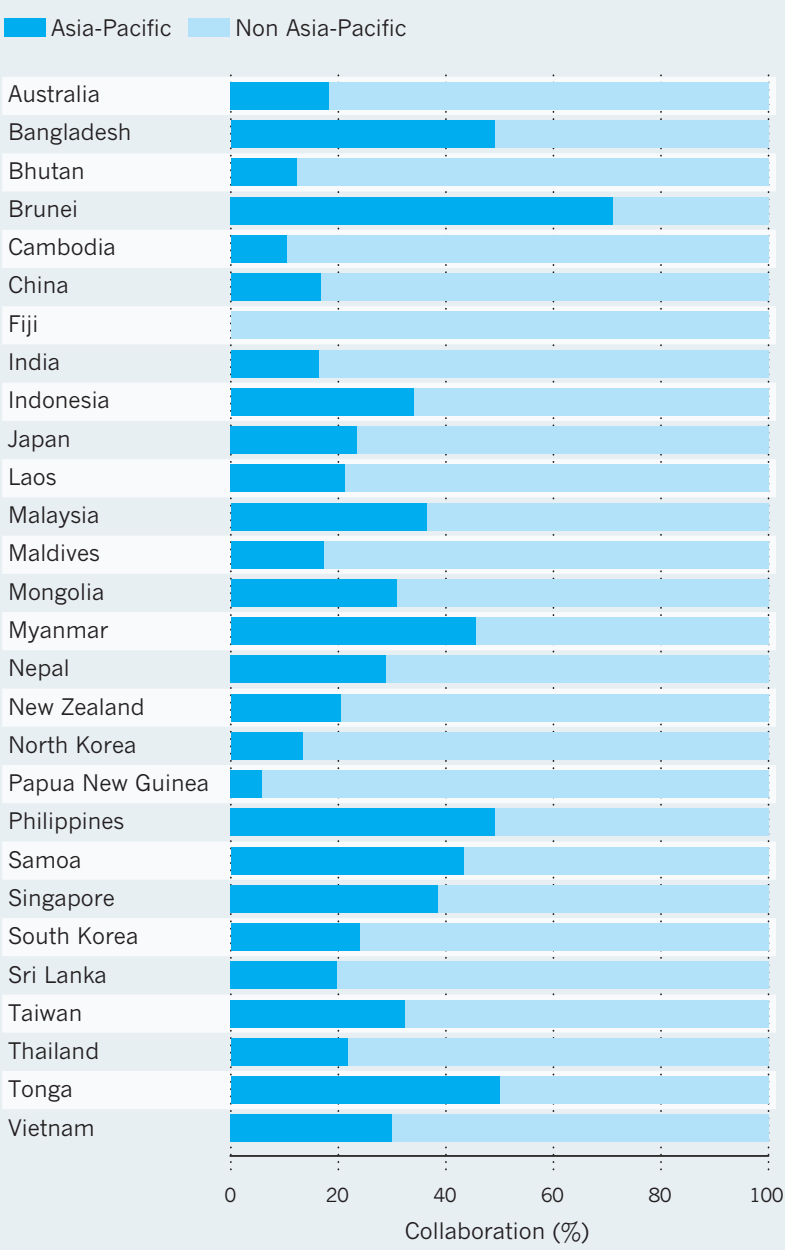

